\title{
A DinÂMica InStitucional: UMA REFLEX̃̃o SOBRE O ALCANCE DAS INSTITUIÇÕES ${ }^{1}$
}

\author{
Institutional Dynamics: a reflection on the range of institutions
}

\section{Guillermo Cruz}

Mestre em Administração pela UFRGS. Doutorando em Administração na área de Estudos Organizacionais no PPGA/UFRGS. Porto Alegre, RS, Brasil.E-mail: guillermo.cruz@ufrgs.br

\section{Resumo}

Qual o alcance das instituições? Tomando tal questão como ponto de partida desta reflexão e a mantendo como plano de fundo desses pensamentos soltos discute-se alguns dos principais tópicos que permeiam as abordagens institucionais, como a definição de instituição, a delimitação de espaços institucionais e a mudança institucional. Propõe-se que as instituições tenham um alcance fluído, que possuam elementoschave que determinem sua perduração e que instituições puras coexistam com instituições mutantes no espaço institucional. Tais características reforçam a importância da consideração de uma realidade cada vez mais fluída permeada por uma dinâmica institucional.

Palavras-chave: Institucionalismo. Lógica institucional. Campo organizacional. Modernidade Líquida. Ensaio Teórico.

\section{Abstract}

What is the range of institutions? Taking this simple question as starting point of my reflection, I am going to revisit some of the main topics that underlie the institutional approaches, such as the definition of institution, the delimitation of institutional spaces, and institutional change. I propose that institutions have a fluid reach, they are pervaded by key elements that determine its perdurability and that pure and mutant institutions coexist within the institutional space. These features reinforce the importance of considering an increasingly fluid reality pervaded by an institutional dynamics.

Keywords: Institutionalism. Institutional Logics. Organizational Field. Liquid Modernity. Essay. 


\section{INTRODUÇÃo}

Poucas coisas intrigam tanto a mente humana quanto a reflexão acerca de sua própria existência e sobre aquilo que se encontra ao seu redor. Neste aspecto, reflexões acerca da realidade povoaram a mente dos mais diversos pensadores ao longo da história da humanidade: seja com Descartes (2009) e a prática de uma dúvida radical para dar origem a um método cartesiano de apreensão dos conhecimentos; seja com a escola empirista de Hume (2000) e Locke (1999) ao questionar a consideração de ideias inatas cartesianas e basear a apreensão de seus conhecimentos puramente nos sentidos; ou então com os fenomenólogos, como Husserl (1990), a propor para o indivíduo a procura pela essência daquilo que a nós é apresentado no mundo real; ou quem sabe ainda pelo questionamento de Arendt (2009) da existência dessa essência, eternamente ameaçada pelas impenetráveis aparências da realidade; e seja por tantos outros estudos e perspectivas que poderiam facilmente preencher infinitas linhas deste breve ensaio e, neste caso, levar à destruição de sua brevidade. Certamente não faltam exemplos, tampouco questionamentos. E o que se pode dizer quando, ao invés de se considerar a apreensão desta realidade em um dado instante "congelado" do espaço-tempo, se pega os distintos elementos de uma realidade "em movimento", com o passar de meses, anos, décadas, com seus diferentes elementos a convergir para um determinado estado, ou a divergir para o desconhecido ou mesmo para o desaparecimento? Nesse ponto desta reflexão, eis que uma palavra aparece no horizonte: modernidade.

Considerado como um dos principais autores nas discussões sobre a modernidade, Max Weber (2001) a via como um processo de "desencantamento do mundo", de perda das referências mítico-religiosas que, para o homem de uma sociedade centrada na tradição, davam sentido e coerência à experiência e ao destino. Em outras palavras, Weber apontava para o triunfo da racionalidade instrumental na vida humana associada, com uma ordem racionalista aprisionando a humanidade em uma "gaiola de ferro" até o dia em "[...] que seja queimada a última tonelada de carvão fóssil" (WEBER, 2001, p. 140). Nesse aspecto, a burocracia, apresentando-se como a manifestação organizacional do espírito racional, acaba por constituir- -se na forma mais eficaz de controle dos indivíduos, impondo a estes, entre outros aspectos: a divisão do trabalho, a organização hierárquica, a impessoalidade $e$, principalmente, a formalização de regras em leis que garantiam a legitimidade da forma burocrática (tal como as normas e valores sociais).

A imagem de uma sociedade rígida visualizada por Weber, presa em uma gaiola de ferro de normas, leis e regras, assombrou diferentes pensadores em suas tentativas de visualizar/representar o futuro da humanidade, seja por meio de teorias ou mesmo por meio de fábulas. Duas visualizações famosas sobre o futuro são as estórias apresentadas por Aldous Huxley em Admirável Mundo Novo e por George Orwell em 1984, as quais compartilhavam a visão de um mundo estritamente controlador que levava ao extremo os aspectos presentes na realidade que os autores vivenciavam. No mundo de Huxley, todos os homens eram controlados desde a geração por um sistema que aliava controle genético (predestinação) à condicionamento mental, o que os tornava dominados pelo sistema em prol de uma aparente harmonia na sociedade. Na distopia de Orwell, por sua vez, a sociedade é completamente dominada pelo Estado, em que ninguém escapa à vigilância invasiva $e$ frequente realizada pelo regime totalitário do "Grande Irmão" por meio de telas bidirecionais que colocavam os indivíduos em uma espécie de "panóptico" dentro de suas próprias residências.

Tais realidades retratadas nas obras de Huxley e Orwell poderiam muito bem ser classificadas como "discurso de Joshua" sob a ótica dos discursos de Thrift $(2005)^{2}$. Para ele, os discursos representam "[...] metalinguagens que instruem as pessoas a como viver como pessoas [...]", sendo o discurso de Joshua fundado na ideia de uma racionalidade transcendental que implica a imagem de um mundo "[...] centralmente organizado, rigidamente delimitado e histericamente preocupado com fronteiras impenetráveis" (THRIFT, 2005, p. 24). Aqui, o discurso de Joshua se opõe ao que Thrift chama de "discurso do Gênesis", uma visão de mundo na qual as fronteiras não têm mais uma importância fundamental, sendo as fronteiras territoriais, temáticas e ideológicas tênues, obscuras e confusas. Assim, "[...] enquanto no discurso de Joshua a ordem é a regra e a desordem, uma exceção, no discurso do Gênesis a 
desordem é a regra e a ordem, uma exceção". (THRIFT, 2005, p. 26)

Adotando uma abordagem pós-moderna, Bauman (2001) defende que a realidade atual está mais próxima do discurso do Gênesis do que do discurso de Joshua. Ele apresenta em sua obra uma descrição da presente fase da modernidade, "nova" em certos aspectos, na qual ocorre a passagem de uma modernidade sólida e pesada para outra leve e líquida, muito mais dinâmica. $\mathrm{O}$ que a distingue tal modernidade líquida de todas as outras formas de modernidade teorizadas é a "[...] compulsiva e obsessiva, contínua e irrefreável e sempre incompleta modernização; a opressiva e inerradicável, insaciável sede de destruição criativa" (BAUMAN, 2001, p. 36 grifo do autor). Nesse aspecto, os padrões de dependência e interação são agora maleáveis, não mantendo a sua forma por muito tempo, tal como os fluídos. Não demandam assim a vigilância constante e o esforço perpétuo de controle aplicável aos sistemas sólidos. Não existe mais o "Grande Irmão à espreita".

Tal realidade apresentada por Bauman (2001) leva-nos a refletir sobre uma conhecida corrente teórica dos estudos organizacionais: o institucionalismo, que vem passando ao longo de sua história por distintas fases, tendo sido dividido por muito tempo em "velho" e "novo", sendo a primeira expressão normalmente vinculada às teorias apresentas por Phillip Selznick $e$ a segunda associada a uma vertente surgida a partir do final dos anos de 1970, que tem como alguns de seus ícones as obras de Meyer e Rowan (1977) e DiMaggio e Powell (1983). Como em seus primórdios, o institucionalismo buscou descrever a forma como organizações passam por uma "infusão de valor", trazendo para si características da comunidade local em que estava circunscrita (SELZNICK, 1971), em sua versão renovada o institucionalismo teve como uma de suas principais preocupações a estabilidade das estruturas organizacionais e a forma como as organizações buscavam se tornar isomórficas com o ambiente onde estavam inseridas de modo a obter legitimidade.

Nesse ponto, os caminhos tomados pelo institucionalismo conduzem naturalmente a uma questão principal e a tantas outras que assolam a mente de institucionalistas contemporâneos: se as organizações estão sempre buscando legitimar-se através da conformação com pressões do ambiente externo $e$, dessa forma, sendo conduzidas a estados de aparente estabilidade ou homogeneidade, como explicar a ocorrência de mudança no contexto organizacional? Ainda, considerando-se um contexto cujas mudanças se tornassem cada vez mais frequentes, que significado adquirem as instituições? Como se pode definir o que é uma instituição e o que a compõe?

A seguir tais questões serão avaliadas tendo como pano de fundo outra questão não menos relevante: qual o alcance das instituições? Pretende-se, por meio da consideração dos limites das instituições, propor uma revisão do próprio significado das instituições $e$ como estas estão envolvidas com uma realidade que se apresenta cada vez mais dinâmica e "líquida".

\section{Uma Breve História das Instituições E SEUS LIMITES}

O estudo de instituições possui uma longa história nos estudos organizacionais, tendo como uma parte significativa de seus trabalhos precursores os estudos realizados por Phillip Selznick (1949; 1971). Ao considerar a diferença entre o que caracteriza uma organização e o que caracteriza uma instituição, Selznick (1971) viria a apresentar aquilo que é tido por muitos como o "velho institucionalismo". Para ele, uma organização poderia ser descrita como "[...] um instrumento técnico para a mobilização das energias humanas, visando uma finalidade já estabelecida [...]" (SELZNICK, 1971, p. 5), sendo indiferentes os fatores sociais em suas ações. Tinha-se, desse modo, a concepção da organização como um instrumento racional e projetado para executar um serviço. Uma instituição, por sua vez, era definida por Selznick como socialmente construída, fruto das necessidades e das pressões dos indivíduos que a compõe e que com ela interagem. Assim, a institucionalização refletiria um processo de "infusão de valores" por parte das organizações, quando elas "[...] passam a simbolizar as aspirações da comunidade, o seu senso de identidade" (SELZNICK, 1971, p. 17). Essa "infusão de valor" ocorreria de maneira tal como descrita pelo mecanismo de "cooptação" na qual uma liderança local era trazida para dentro da organização, ou seja, cooptada, levando consigo seus valores (pessoais) e os valores de sua comunidade, harmonizando assim, as relações da organização - já podendo agora 
ser denominada "instituição" - e a comunidade local onde ela está inserida. (SELZNICK, 1949)

Inspirados nos estudos da burocracia realizados por Weber, a partir da década de 1970 autores do chamado neoinstitucionalismo viriam a propor uma nova explicação para a crescente homogeneidade na realidade organizacional. Meyer e Rowan (1977), por exemplo, justificariam tal homogeneidade como resultante da conformação das organizações ao adotar mitos e práticas institucionalizados no ambiente. De acordo com eles, as organizações alteram suas estruturas formais com o objetivo de ganhar legitimidade, adaptando-se de acordo com os mitos institucionalizados no ambiente, evitando assim o risco de serem rotuladas de negligentes, irracionais, ou mesmo, desnecessárias. As mudanças estruturais não ocorreriam nas organizações devido a questões de eficiência ou necessidade de enfrentamento da concorrência, mas antes, devido a processos que as tornam mais semelhantes sem torná-las mais eficazes do que eram (DIMAGGIO; POWELL, 1983). Conforme lembra Zucker (1987, p. 445), a "[...] conformidade organizacional com o ambiente institucional simultaneamente aumenta a avaliação positiva, o fluxo de recursos e, portanto, as chances de sobrevivência, e reduz a eficiência".

Sob tal perspectiva, Meyer e Rowan (1977) definem o processo de institucionalização como "[...] os modos pelos quais processos sociais, obrigações ou atualidades passam a ter um status de regra no pensamento e na ação social" (MEYER; ROWAN, 1977, p. 341). Em outras palavras, a institucionalização surge como resultado do processo de homogeneização dos campos organizacionais por meio de mecanismos isomórficos: coercitivos, miméticos e normativos. (DIMAGGIO; POWELL, 1983)

Juntas, as versões do velho e do novo institucionalismo apresentam diferenças e semelhanças. Inicialmente, a própria ideia de "instituição" se mostra diversa e, de certo modo, ambígua. Se com Selznick a instituição era "personificada" na imagem de uma organização "infundida de valor", com os neoinstitucionalistas a instituição deixou de ser algo físico/ concreto preso a organização, passando a representar um conjunto de entendimentos, significados e regras compartilhadas presentes nas estruturas sociais, dentro de setores/campos. Outra diferença está presente no processo de institucionalização: enquanto no velho institucionalismo tinha-se um ambiente local repleto de instituições que buscavam se tornar distintas umas das outras, mesmo que de forma não intencional, nos trabalhos precursores do novo institucionalismo há uma preocupação maior com a persistência do que a mudança, com o isomorfismo das organizações com relação a práticas e regras institucionais na busca por recursos e legitimidade (MEYER; ROWAN, 1977) e com a homogeneidade dos campos organizacionais. (DIMAGGIO; POWELL, 1983)

Já entre as semelhanças pode-se citar o fato em ambas as vertentes as organizações se sujeitarem às pressões do ambiente externo e a imposição de um limite fixo para a propagação do que cada escola chama de instituição. Enquanto no velho institucionalismo a instituição acaba nos limites da própria organização (ainda que suas ações refletissem na comunidade local), no novo institucionalismo as fronteiras dos campos e setores delimitavam o alcance das instituições. Nesse aspecto, ambas as vertentes permanecem agarradas a uma representação estática da fronteira das instituições, sendo limitadas para abordar uma noção de realidade dinâmica proposta neste ensaio.

Abordagens recentes na corrente institucional têm tentado preencher algumas das lacunas deixadas por suas predecessoras, em especial as relacionadas ao novo institucionalismo, criticado por não abrir espaço para discussões sobre a mudança, a inovação, o poder $e$, principalmente, sobre a agência. Nesse aspecto têm sido trazidos à tona temas como o empreendedorismo institucional (DIMAGGIO, 1988; HARDY; MAGUIRE, 2008), desinstitucionalização (OLIVER, 1992; DACIN; DACIN, 2008), conflito, poder, agência e habilidade social em campos de ação estratégica (FLIGSTEIN, 2001; 2008) e lógica institucional (FRIEDLAND; ALFORD, 1991; THORNTON; OCASIO, 1999; THORNTON, 2008; REAY; HINNINGS, 2009). Será justamente a partir da noção de lógica institucional que a presente reflexão irá buscar inspiração para a construção de um significado para o termo instituição dentro de uma realidade fluída e dinâmica.

De acordo com Friedland e Alford (1991), cada uma das principais instituições da sociedade, tal como a religião, a família, a democracia, o mercado capitalista, etc., possui uma lógica central. Isto é, cada uma delas apresenta um conjunto de práticas materiais e construções simbólicas que constituem seus princípios 
organizacionais, fazendo parte da vida de indivíduos, organizações e sociedades. Estendendo tal conceito, Thornton e Ocasio (1999, p. 804) definem lógicas institucionais como sendo "[...] padrões históricos, socialmente construídos, de práticas materiais, valores, crenças e regras [...]" a partir dos quais os indivíduos: (a) organizam o tempo e o espaço; (b) reproduzem sua substância material; e (c) provêm significado a sua realidade social.

Considerando tal definição, no presente ensaio se fará uso da lógica institucional para explicitar os elementos que estão dentro das instituições, ou melhor, da palavra instituição e que podem ser utilizados para decompor tal expressão. Nesse aspecto, considero o termo instituições como uma forma de representar os padrões (rotinas, processos, representações), as convenções (normas, regras, tradições), as práticas estabelecidas (rituais, hábitos, cerimônias), os valores e crenças que são socialmente e historicamente construídos/consolidados nas relações entre indivíduos.

\section{Nos LiMites dAs Instituições: QUESTÕES SOBRE A PUREZA E A APARÊNCIA}

Considerando algumas das diferentes vertentes teóricas dos estudos das instituições, e com isso preestabelecer uma definição utilizável para a palavra instituição, dar-se-á continuidade à presente reflexão estendendo esse termo e o que está por de trás dele. Para tanto, retoma-se aqui a questão de nossa reflexão: qual o alcance das instituições? Para auxiliar na busca por uma resposta a tal questionamento é importante estabelecer algumas proposições para guiar essa busca, a começar pela primeira e mais básica:

Proposição 1 - As instituições possuem um alcance e os seus limites (ou fronteiras) não são estáticos, mas fluídos.

Implícito a essa proposição está a ideia de que as instituições se propagam em um espaço multi-institucional e que tal propagação não segue infinitamente, mas atinge um limite, no qual não se pode mais observar claramente os traços da instituição original. De modo que, ao se considerar os elementos que fazem parte de sua lógica institucional, seus símbolos, seus rituais, seus mitos, e analisar a distribuição deles pelo espaço, será possível chegar a um ponto no qual os elementos constituintes das categorias internas da lógica institucional alcançam um grau tão elevado de distinção entre si e entre os elementos da lógica originária, isto é, da lógica institucional "pura", que ultrapassa os limites abrangidos pela instituição.

Nesse ponto, propõe-se que a instituição não está distribuída no espaço de forma fixa, de modo que sua fronteira pudesse ser desenhada como as fronteiras de uma nação, que precisasse constantemente ser defendida das ameaças de outras instituições e lógicas institucionais. Antes, essa distribuição irá flutuar no espaço-tempo. Com a passagem do tempo os limites que definem os alcances das instituições irão aumentar ou diminuir constantemente conforme o resultado da constante interação desta com o ambiente e, especialmente, com as demais instituições presentes em seu meio.

De modo semelhante aos setores societários descritos por Scott e Meyer (1991), que não possuem uma fronteira espacial bem definida e cujas organizações que não se encontram em um mesmo espaço (físico) podem pertencer a um mesmo setor, propõe-se nesta reflexão que é possível igualmente afirmar que organizações que não estão no mesmo espaço físico podem compartilhar uma lógica institucional semelhante. A propagação das instituições não se dá apenas no espaço físico e objetivo, mas igualmente por um espaço subjetivo (simbólico). Isto é, as instituições podem ser vistas como "[...] simultaneamente materiais e simbólicas" (FRIEDLAND; ALFORD, 1991, p. 241). E nesse ponto chega-se a uma segunda proposição:

Proposição 2 - As instituições não são adotadas em suas formas "puras", mas são adaptadas, sofrendo mutações e distorções.

Conforme apresentado anteriormente, na nova teoria institucional, as instituições eram apresentadas como puras. As organizações, grosso modo, tornavam-se homogêneas em torno de determinadas práticas e mitos, adotando tais mitos e práticas de modo basicamente idêntico. Isto é, elas compartilhavam uma lógica institucional que se pressupunha que seria igual para todas as organizações dentro dos limites do espaço institucional (campo ou setor).

A própria questão da eficiência pode ser retomada aqui. Um dos problemas que os neoinstitucionalis- 
tas precisaram lidar foi a aparente incompatibilidade entre a adoção de práticas consideradas legítimas $e$ o aumento da eficiência. As organizações buscavam se conformar com a pressão institucional proveniente do ambiente onde estavam localizadas e, ao mesmo tempo, precisavam manter-se eficientes. Mas e quando a lógica institucional contrariasse o princípio da eficiência? Aqui Meyer e Rowan (1977) introduziram a noção de que as organizações realizavam o controle da eficiência de modo cerimonial, sendo essencial a crença na boa fé das organizações presentes no campo de que todas as demais estavam de fato respondendo positivamente às pressões do campo $e$ adotando determinada prática ou ritual institucionalizado neste. Tal conformismo lhes assegurava acesso a recursos, independentemente de se isso resultaria em uma eficiência superior (DIMAGGGIO; POWELL, 1983). Assim, as organizações apresentavam-se todas homogêneas no espaço institucional dos precursores do neoinstitucionalismo. Mas, seria essa uma real homogeneidade? Ou ainda, inspirando-se a noção de realidade presente na obra de Hannah Arendt, não seria esta homogeneidade somente uma aparência de algo que estava sofrendo uma mutação?

Nesse ponto pode ser mais interessante, e quem sabe mais próximo da realidade, questionar tal homogeneidade absoluta entre as organizações que fazem parte de um determinado espaço institucional e propor adoção do pensamento oposto a este determinismo no qual as organizações e indivíduos se comportam como "receptores passivos" das instituições (FLIGSTEIN, 2008). Torna-se relevante a consideração de um espaço no qual as organizações ajam como participantes que interagem ativamente em um campo ao mesmo tempo "igual" e "mutante". Que as organizações estão imersas em um espaço que, ao mesmo tempo, as condiciona a serem semelhantes e que também as inspira a serem diferentes. Um espaço no qual estrutura e agência se encontrem "recursivamente implicadas". (MACHADO-DA-SILVA; GUARIDO FILHO; ROSSONI, 2006)

Tendo isso em vista, defende-se que as organizações tomam a lógica institucional presente no ambiente do qual fazem parte, a avaliam e a adaptam. Ou seja, ao serem propagadas entre as organizações no espaço-tempo, as instituições vão sendo adaptadas à estrutura da organização, às crenças, mitos e símbolos nela existentes. Em um caso extremo, tal adaptação pode ser tão drástica que leve a uma mutação da instituição dominante, criando assim uma nova instituição, mutante e emergente no campo institucional.

De forma resumida, o resultado final desse processo de "adaptação/mutação" vai ser algo diferente do que estava posto tanto interna quanto externamente $e$, tomado pelo ponto de vista externo à organização, do ponto de vista daquela instituição que se propaga no ambiente/espaço, será qualquer coisa, mas não será aquela "instituição pura" original. E assim, reformulando-se o que já foi dito, chegou-ses a uma terceira proposição:

Proposição 3 - Tem-se em um mesmo espaço institucional a coexistência de instituições mutantes e instituições puras.

Quanto mais distante do "centro" de uma instituição, da sua origem ou, ainda, do seu "marco zero", não só espacialmente (espaço real/visível), mas também subjetivamente (no espaço-tempo simbólico), por entre as culturas, os rituais e as tradições, maiores serão as diferenças observadas quanto ao modo como essas organizações adotam determinada instituição. Em outras palavras, mais diferenças se encontrará entre a instituição em sua forma pura nos entornos no marco zero e a instituição mutante das periferias. De modo que, em um determinado espaço de tempo, podem coexistir, em um mesmo espaço, duas lógicas institucionais diferentes. (REAY; HINNINGS, 2009)

Aqui é possível retomar a representação feita por Fligstein (2008) dos campos de ação estratégica em que as organizações estão imersas, os quais apresentam tanto atores que podem ser classificados como dominantes (incumbentes) quanto atores classificados como desafiantes (challengers). Enquanto os grupos dominantes irão fazer uso de determinada lógica institucional para manter seu poder e legitimidade no campo, os grupos desafiantes estarão à espera de oportunidades para mudar o que está legitimado no campo. Fazendo um paralelo com o que foi já foi apresentado ter-se-ia, grosso modo, grupos dominantes propagando e reforçando uma lógica institucional a partir do "marco zero" no qual se encontram posicionados no espaço multi-institucional, ao mesmo tempo em que grupos desafiantes estarão "distorcendo" a lógica dominante e buscando a oportunidade de lançar uma resposta 
diferente no espaço, que reflita as inconformidades encontradas na lógica dominante.

Agora, é possível voltar à questão norteadora de nossa reflexão: qual o alcance das instituições? Apresentei acima algumas proposições que ajudaram a situar tal questionamento em um ambiente dinâmico, em que é possível destacar: a coexistência de instituições puras e mutantes; instituições fluindo através da propagação de elementos de sua lógica institucional por meio dos diferentes atores presentes no campo; $e$ uma gama de organizações e instituições em constante estado de disputa. Por trás de tal realidade, está um universo de impulsos e respostas, em que as organizações ao mesmo tempo em que propagam ou reforçam uma lógica institucional também respondem a outras que estão sendo propagadas ou reforçadas. Para visualizar tal dinâmica pode-se tentar fazer uso de uma analogia.

\section{A Analogia do Lago: o universo DAS RESPOSTAS E O CAOS DO CAMPO DINÂMICO}

Como imaginar um espaço de múltiplas instituições e lógicas institucionais interagindo entre si, reforçando-se, destruindo-se ou, ainda, combinando-se? Ou então, de modo oposto, como imaginar a total ausência de instituições? Enquanto no primeiro caso um cenário confuso e caótico se apresentaria na tarefa de abstração pensada, no segundo a confusão não seria menor, sendo tão problemática quanto imaginar o nada. De modo a simplificar tal tarefa, escolheu-se aqui um meio-termo, fazendo uso de um pequeno exercício de abstração, nos mesmos moldes que ícones das ciências exatas como Einstein ou mesmo antigos filósofos como Platão e Aristóteles empregavam para tentar visualizar suas teorias, tendo como base um exemplo da natureza, que será chamado de a analogia do lago.

Imagina-se um lago, calmo e liso em sua superfície, de modo que se jogue nele pedras, ondas se formariam e poderiam ser identificadas pelo observador externo. Essas ondas se propagariam nesse lago e, se não encontrassem obstáculos, iriam, com o passar do tempo, diminuindo de intensidade até desaparecer pela dissipação da energia potencial inserida no lago quando a pedra foi nele jogada. Tem-se aqui uma "imagem mental padrão" da propagação de uma onda
- homogênea, em círculos concêntricos que se afastam de uma origem e que vão diminuindo sua amplitude pelo atrito com as partículas da água.

Considera-se agora, seguindo a abstração, que algo semelhante ocorre com as instituições: que elementos de uma lógica institucional são "jogados" no imenso lago social em que as organizações estão inseridas, causando "ondas" que vão se propagar por esta sociedade, não apenas pelo espaço físico ocupado pelas organizações, mas pelo espaço simbólico que as engloba. Em sua propagação, tal onda poderá encontrar obstáculos, como a própria lógica interna das organizações. De modo que, se fosse possível tirar uma fotografia desse momento, se teria um espaço da onda emitida e seus reflexos, um universo de impulsos e respostas. Ainda, se captasse uma imagem desse espaço de tempos em tempos, em um intervalo $\mathrm{T}$, ter-se-ia em cada um desses intervalos uma imagem diferente.

É importante ressaltar aqui o papel deste intervalo. Não se trata de qualquer intervalo (T). A situação considerando $\mathrm{T}$ como 5 segundos ou $\mathrm{T}$ como 5 anos obviamente não é a mesma. $\mathrm{T}$ em segundos ou dias talvez não revela diferenças significativas, parecendo homogêneo aos olhos de quem vê. Mas quando $\mathrm{T}$ tende ao intervalo de anos, 5, 10, 100, começará a se observar mudanças graduais na distribuição das dos elementos de nossa fotografia. Um determinado elemento da lógica institucional pode começar a diminuir seu domínio, atenunado assim os limites daquele campo, ou pode aumentar, se mesclar com outro, novos pontos de outras cores podem também surgir, dando origem a novas instituições, uma redistribuição das existentes. As possibilidades de combinação são múltiplas.

Pode-se tentar pensar a organização do mesmo modo que a pedra em nosso lago imaginário, "emitindo" determinada prática em seu ambiente, prática esta carregada de símbolos e significados, carregada de elementos de uma lógica institucional, propondo sua própria lógica interna ao ambiente por meio desta prática emitida, colocando sua lógica e os elementos que a caracterizam como "a mais correta". O "ambiente" ao seu redor, por sua vez, irá responder a esse impulso, de modo que a "onda" emitida pela organização localizada no marco zero do lago imaginário irá refletir nos obstáculos presentes neste, irá "bater" nas organizações que nele se apresentam imersas e "voltar", isto é, as 
organizações presentes neste campo responderão a este impulso, e tal resposta pode ocorrer de distintas formas.

Porém, nesse "espaço-lago" abstraído pode haver um pouco mais de complexidade. As "ondas" emitidas são inicialmente "absorvidas" pelas organizações, ou melhor, processadas dentro delas, para então ser apresentada uma resposta, que pode ser igual, reforçando a lógica dominante ou distorcida, na forma de um novo "sinal", de uma nova "onda". Ainda, nesse espaço-lago não haverá apenas a calmaria e então uma única onda, mas um mesclado de ondas e estabilidade, múltiplas instituições estabilizadas, estabilizantes ou em processo de instabilidade. Utilizando-se ainda dessa analogia, haverá diversas "ondas" interagindo umas com as outras, sendo impulsionadas a partir de pontos centrais e refletindo-se no que está a sua volta. E haverá, principalmente, não um espaço estável e sólido, mas um espaço caótico e fluído. Nesse ponto chega-se a mais uma proposição:

Proposição 4 - As instituições estão presentes em um ambiente caótico e dinâmico.

As instituições estão presentes em um universo de respostas organizacionais, em um mar de lógicas institucionais interpenetradas, uma realidade em muitos aspectos caótica e dinâmica. Desse modo, haverá no campo, por assim dizer, diversas vozes, cada qual falando suas preferências, sua lógica. Algumas tentando ser transparentes, mostrando exatamente o que são, o que pensam, seja igual ou diferente o que é posto como certo no ambiente a sua volta, enquanto outras estarão tentando utilizar uma máscara, mostrando algo parcial, algo aparente, deixando verdades escondidas, seja para se mostrarem em concordância com as pressões ambientais do "correto" (ou melhor, do "adequado", do "legítimo"), seja para mostrar apenas uma pequena discordância, não querendo mostrar a total aberração, a total inconsistência, que possa existir dentro de si com relação ao que é tido como legítimo, como um iceberg mostrando apenas a ponta de sua composição e deixando todo o resto "submerso" nas profundezas do que não é dito ou refletido ${ }^{3}$. E em meio a tantas vozes, algumas talvez falem "mais alto", lutando/discutindo em uma batalha para ver quem fala mais alto, quem passará a ter a "voz dominante" no campo. Mas o que faz umas "falarem mais alto" que outras? Nesse ponto cabe mais uma proposição:
Proposição 5 - Os espaços institucionais (campos ou setores) são arenas de lutas entre organizações pela legitimidade nestes.

Conforme destaca Fligstein (2001; 2008), os campos, setores ou domínios, podem ser entendidos como arenas institucionalizadas de interação, em que ocorre a ação social. Nelas, atores com capacidades organizacionais diferentes referenciam seu comportamento com relação uns aos outros: tomam como base as regras presentes no campo, as interpretam $e$, avaliando seus próprios interesses, decidem, estrategicamente, qual ação tomar. Para tanto, é demandada a criação de uma cultura local, a qual contém elementos cognitivos que servem como um framework interpretativo para os atores presentes no campo e, ainda, que "[...] define as relações sociais, e ajuda as pessoas a interpretar sua posição em um conjunto de relações sociais" (FLIGSTEIN, 2001, p. 15). No presente ensaio considera-se esses elementos cognitivos como constituintes da lógica institucional, das normas, dos mitos e dos símbolos presentes nas instituições.

Assim, retomando o que foi dito anteriormente, para determinadas organizações no campo poderem "falar mais alto" do que as demais devem elas de certo ter algo que as capacite a "gritar" para as demais de modo "mais claro" e "mais alto" (em alto e bom som). Devem ter elas "elementos diferenciados" (características, capacidades, recursos, etc.) que lhes conceda certa influência dentro do espaço em que fazem parte. De modo análogo, pode-se aqui imaginar uma sala com muitos indivíduos, todos falando ao mesmo tempo: como falar baixo é pedir para não ser ouvido, não falar é o mesmo que aceitar o que está posto ou simplesmente, abster-se. Então, nesta sala, para ser ouvido o indivíduo deve falar um pouco mais alto, mas não basta a ele apenas gritar palavras quaisquer, elas devem fazer algum sentido para os demais, para a situação/realidade presente, para a discussão em andamento. Deve haver uma consistência combinada com essa intensidade (ou "força") do grito. E nesse ponto é possível voltar a falar do campo, das instituições, de seus atores e, principalmente desta questão norteadora: o alcance das instituições. 


\section{Força, Consistência e Perduração DAS INSTITUIÇÕES}

Então, qual o alcance das instituições? Propõe-se aqui que esse alcance está relacionado ao que foi tratado no início desta reflexão: para a força da instituição e dos elementos de sua lógica institucional; e para a consistência da instituição com as requisições de seu contexto. Mas o que seria uma instituição consistente, de fato? Seria apenas aquela que ao ser proposta estava de acordo com as requisições do ambiente? E uma instituição forte? Seria a que aplica mecanismos coercitivos eficientes sobre os demais atores no ambiente? Questões como essas nos levam a sexta e última proposição deste ensaio:

Proposição 6 - A perduração de uma instituição está associada a sua força e sua consistência.

Ao falar de força pretende-se aqui retomar uma das características que se pode abstrair da analogia do lago feita anteriormente, isto é a "amplitude" da onda. Aquela amplitude estava intimamente ligada às características da pedra que foi jogada no lago, estando estas entrelaçadas com a energia potencial que a pedra poderia imprimir na água. Tais características poderiam ser o seu diâmetro, o seu peso ou mesmo a composição de seus elementos. Nessa reflexão quando se fala em instituições pode-se pensar em algo semelhante, em que a força de uma instituição pode estar ligada às características de sua lógica institucional, as quais por sua vez dependem igualmente das características da organização que propaga tal instituição. Tem tal organização capacidades internas que se diferenciam das que as outras organizações possuem? Tem tal organização recursos ${ }^{4}$ suficientes para levar sua lógica institucional tanto para as camadas microssociais quanto para as camadas macrossociais de realidade? Tem tal organização acesso aos diferentes tipos de conhecimento demandados em seu campo de ação? Pressupõe-se que respostas positivas para questões como esta constituem bons indicativos iniciais para a força de uma instituição.

$\mathrm{E}$, por consistência, o que se pode entender? Defende-se que a instituição mais consistente com o ambiente e as pressões oriundas deste seria uma instituição dinâmica e fluída, aquela que está mais apta a adaptações, que está mais apta a ser moldada ao longo de sua existência. Nesse ponto a organização que propaga e reforça uma determinada lógica dominante deve estar ciente das oportunidades de mudança que sua própria lógica oferece tanto quanto estarão organizações desafiantes, que estão à espreita procurando oportunidades para inovar. Aquelas organizações que tentam produzir um sistema de dominação dentro de um campo, que tentam manter sua legitimidade dentro desse campo, deverão saber incorporar eventuais mudanças na lógica institucional, incorporando assim "instituições mutantes" para reforçar sua própria lógica institucional com novos elementos de modo similar à forma como a instituição de Selznick realizava a cooptação. Em outras palavras, defende-se, grosso modo, que quanto mais maleável é uma instituição mais ela perdura dentro do ambiente - bem como o poder e a legitimidade da organização que a propaga.

\section{Considerações Finais}

O presente ensaio teve como objetivo propor uma reflexão acerca do alcance das instituições. Tal reflexão põe em questão os diferentes significados dados para as instituições e para o processo de institucionalização em si. Ao invés de pensar nos campos institucionais como estruturas rígidas, consolidadas por mecanismos isomórficos, e convergindo para um estado de homogeneidade entre os atores, é ressaltada aqui a possibilidade de coexistência de múltiplas lógicas institucionais em um campo organizacional fluído, no qual as instituições perduram e se reafirmam também por meio da flexibilização, e cuja mudança é uma característica latente.

A passagem de uma modernidade sólida, pesada, baseada em padrões rígidos, em panópticos, na construção e manutenção constantes da ordem, para uma modernidade fluída, leve, na qual domina a fuga, o desvio, a evitação, em que não é possível mais identificar um poder único e centralizado (nas mãos de um "Grande Irmão"), mas uma infinidade de oportunidades que preenchem "[...] o espaço deixado vazio pelo desaparecimento da Suprema Repartição [...]" (BAUMAN, 2001, p. 23), convida as correntes institucionais a se reformular, abranger cenários que antes não eram possíveis ou mesmo considerados como relevantes, como a mudança, a inovação e o 
conflito. Em outras palavras, uma teoria institucional capaz de representar uma realidade dinâmica.

Nos últimos anos proliferaram estudos buscando trazer maior dinamicidade para as instituições e para o fenômeno de institucionalização. Seja pela inserção de eventos disruptivos ou "choques" externos (MEYER, 1982; HOFFMANN, 1999), desestabilizantes da tessitura institucional existente, recorrendo ao nível individual, valorizando o empreendedorismo institucional (DIMAGGIO, 1988; HARDY; MAGUIRE, 2008) ou mesmo conferindo ênfase às forças desinstitucionalizantes da realidade social (OLIVER, 1992; DACIN; DACIN, 2008), diferentes autores buscaram trazer a institucionalização como um processo, marcado por mudanças em seu percurso. Somam-se a estes os avanços feitos na busca por uma visão alternativa do campo organizacional, como um campo de ação estratégica, permeado pelo conflito de interesses e pela ação de atores socialmente hábeis (FLIGSTEIN, 2001; 2008), o campo por uma lógica estruturacionista em que estrutura e agência se encontram recursivamente implicadas (MACHADO-DA-SILVA; GUARIDO FILHO; ROSSONI, 2006), ou mesmo a linha que trabalha com a visão do campo permeado por diferentes lógicas institucionais, com a mudança surgindo da contradição e conflito entre as diferentes lógicas existentes. (FRIEDLAND; ALFORD, 1991; THORNTON; OCASIO, 1999; THORNTON, 2008; REAY; HINNINGS, 2009)

Seguindo por uma linha semelhante, por meio do uso de algumas abstrações, propõe-se neste ensaio uma representação da propagação das instituições em uma realidade dinâmica e fluída, com tais instituições possuindo um alcance igualmente fluído e variante, coexistindo com outras, sofrendo mutações e distorções, possibilitando a mudança e a inovação e buscando uma perduração por meio de sua força e coerência com o espaço em que estão inseridas. Nesse aspecto, a consideração de uma nova realidade, mais dinâmica e fluída, não significa de modo algum um contexto sem instituições, mas antes, um contexto dotado de uma dinâmica institucional.

Gostaria de agradecer à CAPES pelo suporte financeiro e ao professor Ariston Azevêdo pelos valiosos ensinamentos dados ao longo da disciplina de Epistemologia em Estudos Organizacionais e as discussões que inspiraram a elaboração deste ensaio nos diferentes espaços onde tive a oportunidade de debater as ideias aqui colocadas.

\section{REFERÊNCIAS}

ARENDT, H. A Vida do espírito. Rio de Janeiro: Civilização Brasileira. 2009.

BAUMAN, Z. Modernidade líquida. Rio de Janeiro: Zahar, 2001.

DESCARTES, R. O discurso do método. 4. ed. São Paulo: WMF Martins Fontes, 2009.

DACIN, M.; DACIN, P. Traditions as institutionalized practice: Implications for deinstitutionalization. In: GREENWOOD, R. et al. (Ed.). The Sage handbook of organizational institutionalism. London: Sage, 2008. p. 327-351.

DIMAGGIO, P. Interest and Agency in Institutional Theory. In: ZUCKER, L. G. (Ed.). Institutional patterns and organizations: culture and environment. Cambridge: Ballinger, 1988. p. 3-21.

DIMAGGIO, P.; POWELL, W. The iron cage revisited: institutional isomorphism and collective rationality in organizational fields. American Sociological Review, USA, v. 48, n. 2, p. 147-160, 1983.

FLIGSTEIN, N. Fields, power, and social skill: a critical analysis of the new institutionalisms. International Public Management Review, USA, v. 9, n. 1, p. 227253, 2008.

\section{FLIGSTEIN, N. The architecture of markets: an} economic sociology of twenty-first-century capitalist societies. New Jersey: Princeton University Press, 2001.

FRIEDLAND, R.; ALFORD, R. Bringing society back in: symbols, practices, and institutional contradictions. In: POWELL, W.; DIMAGGIO, P. (Org.). The new institucionalism in organizational analysis. Chicago: University of Chicago Press, 1991. p. 232-263.

JOWITT, K. New world disorder: the leninist extinction. Berkeley: University of California Press, 1992. 
HARDY, C.; MAGUIRE, S. Institutional entrepreneurship. In: GREENWOOD, R. et al. (Ed.). The Sage handbook of organizational institutionalism. London: Sage, 2008. p. 198-217.

HOFFMAN, A. Institutional evolution and change: environmentalism and the U.S. Chemical Industry. Academy of Management Journal, USA, v. 42, n. 4, 1999.

HUME, D. Investigação acerca do entendimento humano. São Paulo: Nova Cultural, 2000.

HUSSERL, E. A ideia da fenomenologia. Lisboa: Edições 70, 1990.

LOCKE, J. Ensaio acerca do entendimento humano. São Paulo: Nova Cultural, 1999.

MACHADO-DA-SILVA, C.; GUARIDO FILHO, E. R.; ROSSONI, L. Campos Organizacionais: seis diferentes leituras e a perspectiva de estruturação. Revista de Administração Contemporânea, São Paulo, ed. especial, p. 159-196, 2006.

MEYER, A. Adapting to environmental jolts.

Administrative Science Quarterly, USA, v. 27, n. 4, p. 515-537, 1982.

MEYER, J.; ROWAN, B. Institutionalized organizations: formal structure as myths and ceremony. American Journal of Sociology, USA, v. 83, n. 2, p. 340-363, 1977.

OLIVER, C. The antecedents of deinstitutionalization.

Organization Studies, USA, v. 13, p. 563-588, 1992.

REAY, T.; HINNINGS, C. Managing the rivalry of competing institutional logics. Organization Studies, USA, v. 30, n. 6, p. 629-652, 2009.

SCOTT, R.; MEYER, J. The organization of societal sectors: propositions and early evidence. In: POWELL, W.; DIMAGGIO, P. (Org). The new institucionalism in organizational analysis. Chicago: University of Chicago Press, 1991. p. 108-140.

SELZNICK, P. TVA and the grass roots. Berkeley: University of California Press, 1949.

SELZNICK, P. A Liderança na administração: uma interpretação sociológica. Rio de Janeiro: FGV, 1971.
THORNTON, P. Institutional logics. In: GREENWOOD, $\mathrm{R}$. et al. (Ed.). The Sage handbook of organizational institutionalism. London: Sage, 2008. p. 99-129.

THORNTON, P.; OCASIO, W. Institutional Logics and the Historical Contingency of Power in Organizations: Executive Succession in the Higher Education Publishing Industry, 1958-1990. American Journal of Sociology, USA, v. 105, n. 3, p. 801-843, 1999.

THRIFT, N. Knowing capitalism. New Delhi: Sage, 2005.

WEBER, M. A Ética protestante e o espírito do capitalismo. São Paulo: Martin Claret, 2001.

ZUCKER, L. Institutional theories of organizations.

Annual Review of Sociology, USA, v. 13, p .443-464, 1987.

1. Uma versão preliminar deste trabalho foi apresentada no III Congreso Internacional Red Pilares promovido pela Red de Posgrados de Investigación Latinos en Administración y Estudios Organizacionales em Porto Alegre, entre os dias 26 e 29 de agosto de 2014.

2. A abordagem dos discursos apresentada em Thrift (2005) é largamente influenciada por Jowitt (1992).

3. Nessa análise reflexiva, tal como qualquer outra análise deve-se ressaltar a ideia da simplificação a qual nos conduz naturalmente a ideia de aparência. O olhar do observador sobre o campo, do cientista social, é uma mera simplificação daquele espaço caótico. É uma avaliação "aos olhos de quem vê", sob a sua perspectiva, considerando as informações que este pesquisador possui, considerando sua experiência de vida, suas relações, o que está instituído em seu próprio olhar. É uma fotografia, uma imagem de um ponto, de um pedaço daquele espaço, no meio de todo um conjunto de ondas e ruídos. Em suma, é uma parcela de todo o caos.

4. Quando se fala em recursos, considera-se aqui não somente o capital econômico de uma organização, mas também outros aspectos, que podem ser expressos, grosso modo, nas técnicas ou tecnologias que ela possui (em uma espécie de capital tecnológico), sua rede de relacionamentos (seu capital social), os signos e representações simbólicas a ela associados (dispostos em seu capital simbólico), etc. 